\title{
Spontaneous Pattern Formation from Focused and Unfocused Ion Beam Irradiation
}

\section{Citation}

Cuenat, Alexandre and Michael J. Aziz. 2002. Spontaneous Pattern Formation from Focused and Unfocused Ion Beam Irradiation. Materials Research Society Symposium Proceedings 696, N2.8.

\section{Published Version}

www.mrs.org/s_mrs/bin.asp?CID=2502\&DID=57810\&DOC=FILE.PDF

\section{Permanent link}

http://nrs.harvard.edu/urn-3:HUL.InstRepos:2797441

\section{Terms of Use}

This article was downloaded from Harvard University's DASH repository, and is made available under the terms and conditions applicable to Other Posted Material, as set forth at http:// nrs.harvard.edu/urn-3:HUL.InstRepos:dash.current.terms-of-use\#LAA

\section{Share Your Story}

The Harvard community has made this article openly available.

Please share how this access benefits you. Submit a story.

Accessibility 


\title{
Spontaneous Pattern Formation from Focused and Unfocused Ion Beam Irradiation
}

Alexandre Cuenat and Michael J. Aziz

Division of Engineering and Applied Sciences, Harvard University, Cambridge, MA 02138.

\begin{abstract}
We study the formation and self-organization of "ripples" and "dots" spontaneously appearing during uniform irradiation of $\mathrm{Si}, \mathrm{Ge}$, and $\mathrm{GaSb}$ with energetic ion beams. Features have been produced both with sub-keV unfocused $\mathrm{Ar}^{+}$ions and with a $30 \mathrm{keV} \mathrm{Ga}{ }^{+}$Focused Ion Beam. We follow the evolution of features from small amplitude to "nanospikes" with increasing ion dose. It appears that the edge of the sputtered region influences the patterns formed, an effect that may make it possible to guide the self-organization by the imposition of lateral boundary conditions on the sputter instability.
\end{abstract}

\section{INTRODUCTION}

Self-organization of surface morphological features to produce structures of potential use in nanotechnology is in its infancy. A few processes leading to self-organized patterns, particularly in heteroepitaxial growth, have been identified and studied. However, control of the selforganization process remains an issue. We have been investigating alternative processes leading to self-organized surface structures - in particular, "sputter patterning" produced by unfocused ion irradiation. Spontaneous rippling of surfaces by ion irradiation was first observed on glass [1]. Similar patterns have been obtained on a variety of materials, including semiconductors [25], metals [6] and insulators [7]. These self-organized patterns have been observed for a wide range of ion energy (from $200 \mathrm{eV}$ to $40 \mathrm{keV}$ ); the orientation of the ripples depends mainly on the incidence angle of the ion beam relative to the sample normal.

The pattern formation mechanism is usually discussed within the linear stability framework of Bradley and Harper [8]. Patterning is due to the dependence of the sputter yield on the curvature of the surface. Because ion energy deposition rate increases as the ion penetrates the solid, concave regions are sputtered more than convex regions, resulting in a growing instability on the surface. This instability is opposed by a smoothening mechanism, e.g. surface diffusion or viscous flow, which has a different dependence on wavelength than the roughening effect. The interplay of these two effects selects a characteristic wavelength for the pattern. This linear theory reproduces many experimental observations [9] but not all [10] [4] [11]. At large amplitudes, nonlinear terms have been proposed [12]. The nonlinear behavior may be especially important in enhancing the uniformity of the size distribution of "quantum dots" recently produced on GaSb surfaces [4] using sub-keV irradiation at normal incidence and room temperature. In this paper, self-organized patterns on $\mathrm{Si}(001)$ and $\mathrm{Ge}(001)$ using both sub-keV unfocused $\mathrm{Ar}^{+}$beam and $30 \mathrm{keV} \mathrm{Ga}{ }^{+}$Focus Ion Beam (FIB) are compared. Boundary effects are shown to have an effect on the self-organization process, opening a way to control the symmetry of the pattern. 


\section{EXPERIMENT}

All unfocused beam experiments are performed in a UHV chamber working at a base pressure of $2 \cdot 10^{-10}$ Torr. The surface is bombarded with $750 \mathrm{eV} \mathrm{Ar}^{+}$from a collimated $3 \mathrm{~cm}$ Kaufman ion gun working at $10^{-4}$ Torr. The sample can be heated to $800{ }^{\circ} \mathrm{C}$ and the angle between the beam and the sample normal can vary from 0 to 70 degrees. Typical ion flux is $0.4 \mathrm{~mA} / \mathrm{cm}^{2}$.

Focused ion beam (FIB) experiments are done using a FEI dual beam FIB-scanning electron microscope (SEM) producing $30 \mathrm{keV} \mathrm{Ga}{ }^{+}$and delivering it to a sample at a pressure of $2 \cdot 10^{-7}$ Torr and room temperature. The incidence angle between the beam and the sample normal can vary from 0 to 60 degrees. The ion beam current can vary from $1 \mathrm{pA}$ to $3 \mathrm{nA}$ and the dwell time at each point was chosen to be $1 \mu$ s. Separation between each spot hit by the FIB is set to have a $50 \%$ overlap for each adjacent point, assuming the beam profile to be gaussian.

Post-irradiated surfaces are observed in air using contact mode AFM.

\section{RESULTS}

Focused and unfocused ion beam induced self-organized patterns. Ripple patterns develop under both sub-keV unfocused $\mathrm{Ar}^{+}$and $\mathrm{Ga}^{+}$FIB irradiations. Here we compare them.

a)

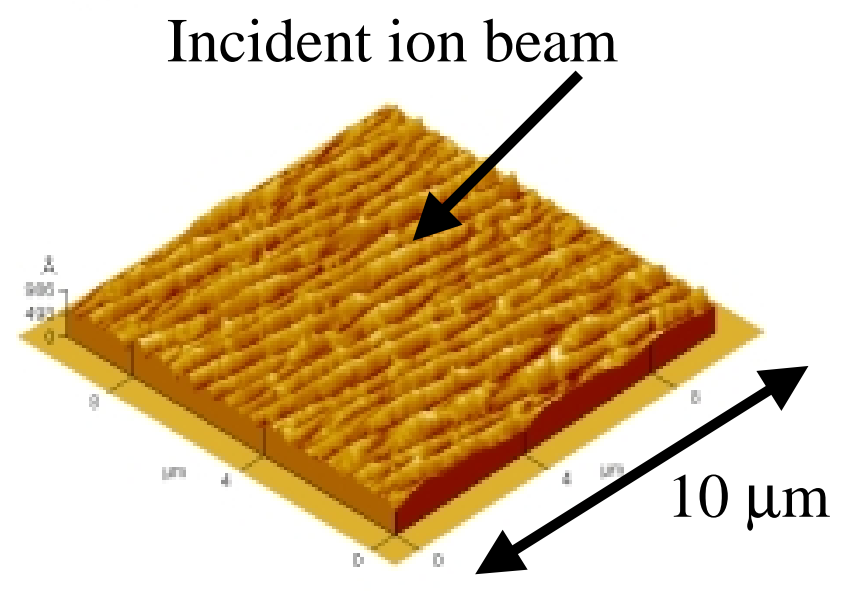

b)

\section{Incident ion beam}

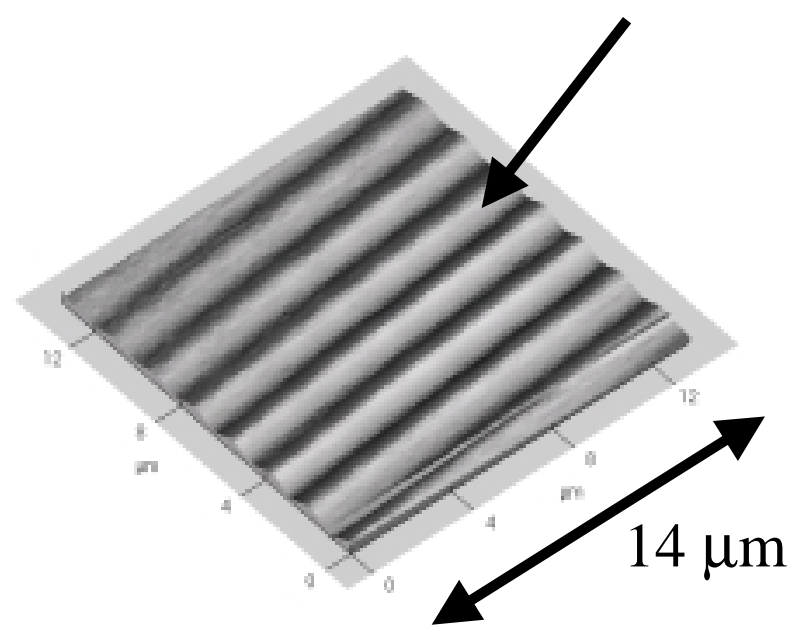

Figure 1. a) Sputter-induced ripples on $\mathrm{Si}(001)$ after bombardment with an unfocused $750 \mathrm{eV}$ $\mathrm{Ar}^{+}$beam at $600{ }^{\circ} \mathrm{C}$. Wavelength $\lambda=520 \mathrm{~nm}$. b) Sputter-induced ripples on Si (001) after bombardment with a focused $30 \mathrm{keV} \mathrm{Ga}^{+}$beam at room temperature. Wavelength $\lambda=2.15 \mu \mathrm{m}$

Fig. 1a shows ripples produced using the unfocused Ar beam. The incident angle is $55^{\circ}$ from normal and the wavevector is perpendicular to the incoming ion beam. The wavelength can be tuned by changing the temperature or the ion flux [9].

Fig. $1 \mathrm{~b}$ shows ripples produced at room temperature using the FIB; the incident angle is $52^{\circ}$ and the beam is rastered over a total irradiated area of $200 \mu \mathrm{m}$ by $200 \mu \mathrm{m}$. The ripple wave 
vector is also perpendicular to the beam direction. The ion beam current is $1054 \mathrm{pA}$ for a beam spot size of 40 $\mathrm{nm}$ and an irradiation time of 20 minutes. Changing the raster direction of the beam or the overlapping percentage between adjacent FIB points does not change the characteristics of the ripples. Figure. 2 shows the morphology resulting from normal-incidence $1 \mathrm{keV} \mathrm{Ar}^{+}$ irradiation of $\mathrm{Si}(001)$ at room temperature for six minutes. The features are qualitatively different from those reported by Gago et al [13] under the same conditions and we cannot reproduce their results. Also, the features are not nearly as regular as the "quantum dots" produced by Facsko et al. on GaSb [4]. The underlying reasons remain a puzzle.

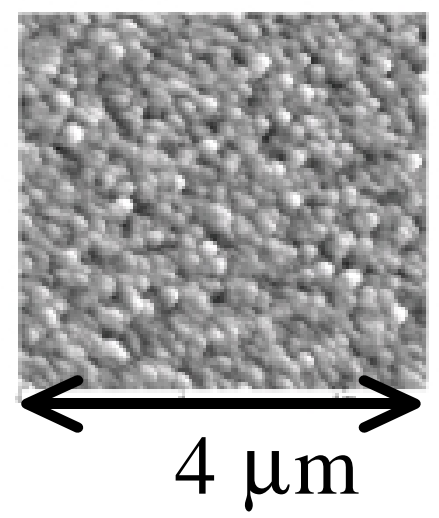

Figure 2. Si (001) bombardment at normal incidence with unfocused 1 $\mathrm{keV} \mathrm{Ar}^{+}$beam at room temperature.

Boundary effects. When the surface evolution is nonlinear, it is interesting to see whether the boundary conditions influence the spontaneously arising pattern. A square $50 \mu \mathrm{m}$ on edge was sputtered away on a $\mathrm{Si}$ (001) surface using the FIB at room temperature. The ion beam current was $1082 \mathrm{pA}$ for a beam spot size of $40 \mathrm{~nm}$ and duration of 20 minutes.

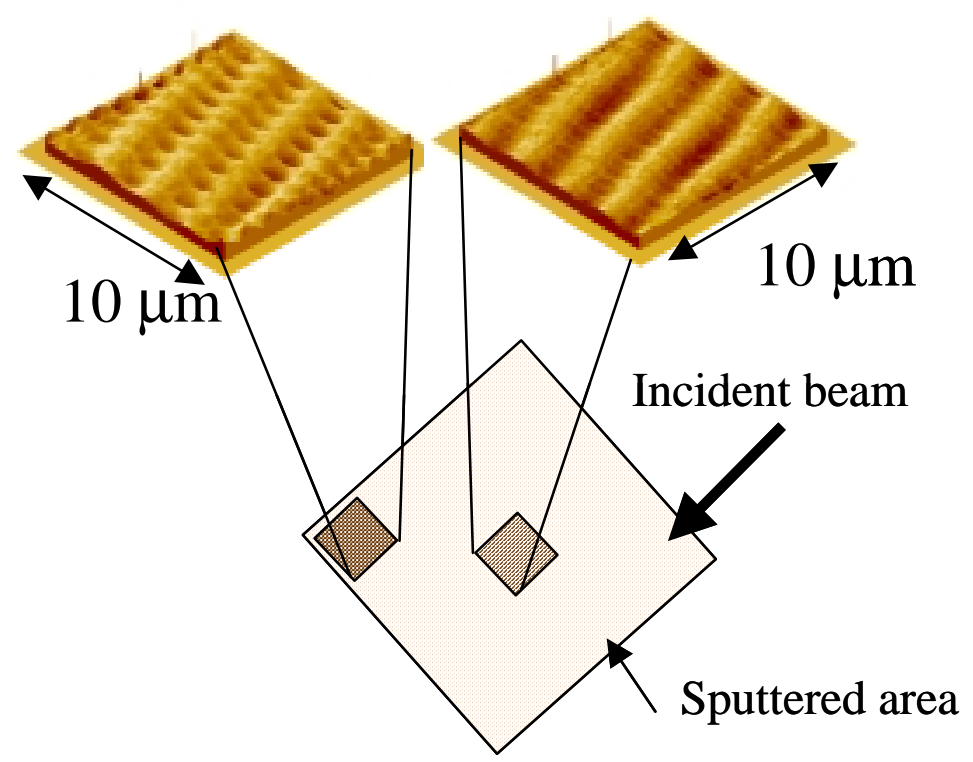

Figure 3. Ion sputter-induced ripples on $\mathrm{Si}(001)$ after bombardment for $20 \mathrm{~min}$. with a focused $30 \mathrm{keV} \mathrm{Ga}{ }^{+}$beam at room temperature in a $(50 \mu \mathrm{m})^{2}$ box. Wavelength $\lambda=2.07 \mu \mathrm{m}$. 
Fig. 3 shows AFM images of two regions of a sputtered square crater. In the center of the square, ripples in the expected orientation are produced. However, near the edge of the box a new symmetry appears. New ripples perpendicular to the previous one are produced, both wavelengths being almost the same. Both ripple directions are parallel to the edge of the square. The amplitude of these new ripples decreases from to 4 to $0 \mathrm{~nm}$, when scanning from the edge of the square to a distance of about $15 \mu \mathrm{m}$. Each corner of the square displays the same new symmetry.

\section{FIB sputtering of Ge and GaSb}

Using the FIB a variety of "rough" surface are observed on Ge (001). For low dose irradiation, small nanometer bumps are produced as shown on Fig. 4a and b. The morphology depends only on the total dose and is independent of the flux or the dose rate. The dots produced are constant in size, but no order is apparent on the surface. This feature can be produced in a very short time (a few seconds), for small irradiated area and large ion beam current, or on a much longer time scale. Even for irradiation as long as 10 minutes, no order is apparent in the Fourier transform of the AFM image.

a)

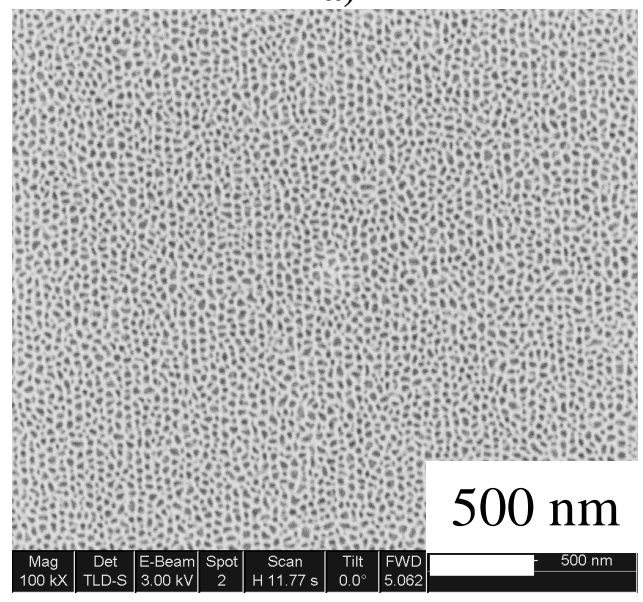

b)

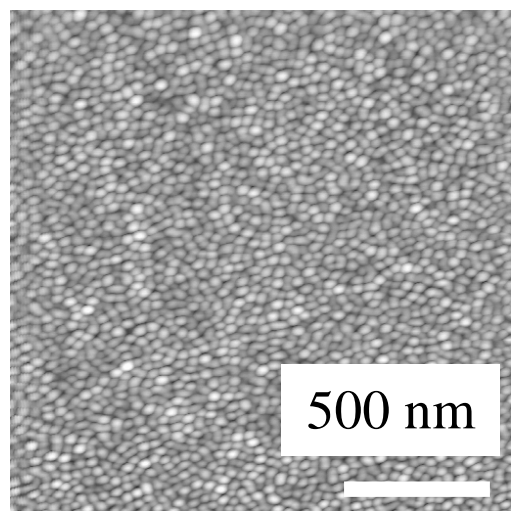

Figure 4. a) SEM image of low dose $\left(3.75 \cdot 1015 / \mathrm{cm}^{2}\right)$ focused $30 \mathrm{keV} \mathrm{Ga}{ }^{+}$irradiation of $\mathrm{Ge}(001)$ surface at room temperature; b) corresponding AFM image.

The surface becomes rougher with increasing dose and, for high enough dose, a qualitatively different "nanospiked" surface is produced (Fig. 5a). The evolution is qualitatively the same for $\mathrm{GaSb}$ (Fig. 5 b) and the rate of morphological progression is much faster on these cases than on $\mathrm{Si}$. These morphologies are reminiscent of those found in room-temperature ion implantation of Ge [14].

\section{DISCUSSION}

Focused and unfocused ion beam experiments permit the study of the self-organization process over a wide range of conditions. Comparison of the resulting morphologies should help unravel the various contributions to morphology evolution associated with this phenomenon. Room temperature irradiation of semiconductors, as is reported here for the FIB experiments, amorphizes the top $100 \mathrm{~nm}$ very early in the irradiation. The higher-temperature, lower-energy 
experiments reported here for the $\mathrm{Ar}^{+}$irradiation permitted the surface to remain crystalline throughout the experiment. One should expect different mass transport mechanisms to dominate these two regimes, perhaps leading to qualitatively different behavior once the nonlinear regime is reached. A model based on adatom surface diffusion during ion irradiation has successfully accounted for experimental observation for high-temperature sub-keV unfocused irradiation [9, 15]. For FIB conditions we are not yet able to conclude whether the smoothening mechanism is due to irradiation induced viscous relaxation of the amorphized layer, nonlinear effects in the instability induced by the ion beam, or other effects. Large variations in ion beam energy should permit us to address this question.

a)

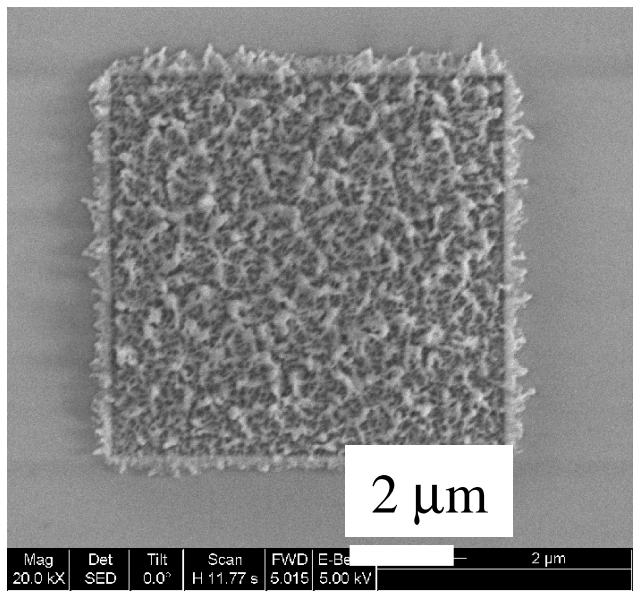

b)

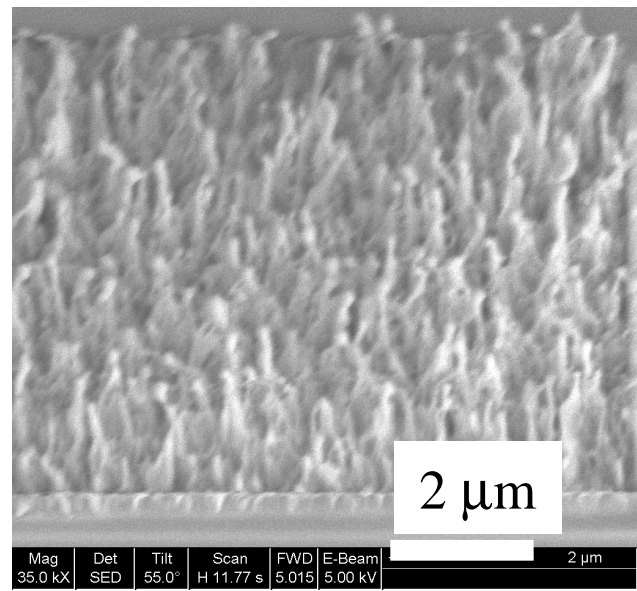

Figure 5. a) High dose $\left(8 \cdot 1017 / \mathrm{cm}^{2}\right)$ FIB irradiation of Ge (001); plan view SEM image. b) Side view SEM image of high dose $\left(5 \cdot 1017 / \mathrm{cm}^{2}\right)$ FIB irradiation of GaSb (001).

The ripples appear to be more regular when produced with the FIB than with the unfocused $\mathrm{Ar}^{+}$beam. This result could be due to differences in beam characteristics or differences in ripple formation mechanisms. Our experiments indicate that it is not due to any synchronization between the pattern and the grid size used in the FIB pattern generation.

That the boundary of the irradiated region changes the pattern formed in its vicinity indicates the possibility of further morphology control in the future. This observation is a first step toward the guided self-organization of surface features using lateral templating. By combining both focused and unfocused ion beam sputtering we hope to be gain a much higher degree of control over the range of morphologies obtainable. 


\section{SUMMARY}

We have produced self-organized patterns on $\mathrm{Si}(001)$ using both focused and unfocused ion beams. The mechanism for the formation of the ripples in the case of FIB is not completely elucidated, but raster effects can be ruled out. A boundary effect on the morphology has been observed for a small box sputtered using the FIB. Nanometer bumps have been produced using the FIB on Ge (001) surface at low dose, the induced topography depending only on the total dose, independent of dose rate. For higher dose, the surface rapidly develops a high aspect ratio "nanospike" structure. The rapid evolution of nanospikes is also observed for GaSb, but not for $\mathrm{Si}$, where we observe disorganized bump.

\section{ACKNOWLEDGMENTS}

This was supported by the Harvard MRSEC, NSF-DMR-98-09363. One of us (A.C.) was supported in part by the Swiss National Science Foundation.

\section{REFERENCES}

1. Navez, M., D. Chaperot, and C. Sella. Comptes Rendus Academie des Sciences, 1962. 254(2): p. 240.

2. $\quad$ Carter, G. and V. Vishnyakov. Phys. Rev. B, 1996. 54: p. 17647.

3. Erlebacher, J.D. and M.J. Aziz. Mater. Res. Soc. Symp. Proc., 1997. 440: p. 461.

4. Facsko, S., T. Dekorsy, C. Koerdt, et al. Science, 1999. 285(5433): p. 1551.

5. Frost, F., A. Schindler, and F. Bigl. Phys. Rev. Lett., 2000. 85(19): p. 4116.

6. $\quad$ Rusponi, S., C. Boragno, and U. Valbusa. Phys. Rev. Lett., 1997. 78: p. 2795.

7. Mayer, T.M., E. Chason, and A.J. Howard. J. Appl. Phys., 1994. 76: p. 1633.

8. Bradley, R.M. and J.M. Harper. J. Vac. Sci. Technol. A, 1988. 6: p. 2390.

9. Erlebacher, J., M. Aziz, E. Chason, et al.. Phys. Rev. Lett., 1999. 82(11): p. 2330.

10. Erlebacher, J., M.J. Aziz, E. Chason, et al.. J. Vac. Sci. Technol. A, 2000. 18(1): p. 115.

11. Habenicht, S., W. Bolse, K.P. Lieb, et al. Phys. Rev. B, 1999. 60(4): p. R2200.

12. Cuerno, R., H.A. Makse, S. Tomassone, et al.. Phys. Rev. Lett., 1995. 75(24): p. 4464.

13. Gago, R., L. Vazquez, R. Cuerno, et al.. Appl. Phys. Lett., 2001. 78(21): p. 3316.

14. Appleton, B.R., O.W. Holland, J. Narayan, et al.. Appl. Phys. Lett., 1982. 41(8): p. 711.

15. Chason, E., J. Erlebacher, M.J. Aziz, et al.. Nucl. Instr. Meth. B, 2001. 178: p. 55. 